\title{
Electron Microscopy Investigations on Catalyst Coatings
}

\author{
Yuan Zhao $^{1}$, Larry Cirjak ${ }^{2}$, Dogan Ozkaya ${ }^{3}$ \\ ${ }^{1}$ Johnson Matthey Process Technologies, Inc. 115 Eli Whitney Blvd, Savannah GA, USA \\ ${ }^{2}$ Johnson Matthey Process Technologies, Inc.785 N. Freedom Street, Ravenna, OH, USA \\ ${ }^{3}$ Johnson Matthey Technology Centre, Blounts Court, Sonning Common, Reading, RG49NH, UK
}

Johnson Matthey develops and manufactures high technology catalysts and chemicals, many of which provide environmental and quality of life benefits, such as automobile emission control catalysts, oil refinery catalysts and additives, catalysts for fine chemicals and fuel cell catalysts etc. In the development and utilization of catalyst materials, especially the precious metals, small particle size and high dispersion on the support are very important to optimize the catalysis performance as well as to get the right combination of porosity and interconnectivity.[1-5] Most of the catalysts are made into products by the use of washcoat coating technology. The catalysts are usually formed into a washcoat with several components and coated on a substrate. The way coating is applied depends on functionality and it can be more than one pass which will result in a system with several layers with different functionalities. One of the biggest problems for transmission electron microscopy is to be able to see all the layers in one sample so that their properties can be related to performance. Here we investigated a two-layer system which contains $\mathrm{Ni}$ on alumina coating as the bottom layer followed by an alumina only layer by using a novel marking method to locate positions of layers.

One such washcoat structure is shown in Figure 1 where the SEM backscattered electron images of a washcoat with two layers are shown. The $1^{\text {st }}$ layer is at the surface and does not contain any Ni but the layer below contains $\mathrm{Ni}$. The way the Ni diffuses into the first layer is very important. SEM resolution limits the observation and microanalysis, and higher resolution analysis is required in case Ni diffuses in small particles. S/TEM would normally be used to investigate the features at high magnifications, but scratching washcoat off substrate and microtoming it would mix the layers and the correlative information between different layers would be lost. The method applied here is to deposit a gold layer on the surface using a sputter coater. The layer beneath the gold layer is the $1^{\text {st }}$ layer. Once the gold layer is deposited, then the washcoat is flaked off and embedded in resin and microtomed. The thin slices can be observed in S/TEM by HAADF imaging as shown in Figure 2. The top layer with high brightness is gold. The $1^{\text {st }}$ and $2^{\text {nd }}$ layers could be found corresponding to the layers observed on SEM images. By using this method, the change in chemistry from the top layer to the bottom one could be studied precisely in S/TEM, such as the Ni diffusion on the top layer (Figure 3). Also, the adhesion and structure between the layers could be studied at higher magnifications. It is clear the adhesion is so good that the only way the layers could be distinguished is the nanoparticulate $\mathrm{Ni}$ content of the layers.

In this presentation, a few case studies of electron microscopy applications in industrial catalysts and materials research and development are presented. The examples of electron microscopy technique development work, such as particle size and distribution analysis, HAADF, bright field and secondary electron imaging optimizations on various samples, will be discussed.

References:

[1] L. C. Gontard, D. Ozkaya, and R. E. Dunin-Borkowski, Ultramicroscopy 111, 101 (2011)

[2] L. C. Gontard, R. E. Dunin-Borkowski, R.K.K. Chong, D. Ozkaya et al, J. Phys. Conf. Ser. 26, 203 (2005). 
[3] Y. Zhao, Y. Tang, G. Vaughan, D. Ozkaya, Microscopy and Microanalysis 18 (S2), 1364 (2012)

[4] Y. Zhao, T. E. Feltes, J. R. Regalbuto et al, Catalysis Letters 141(5), 641 (2011)

[5] Y. Zhao, T. E. Feltes et al, Catalysis Science \& Technology 1(8), 1483 (2011)
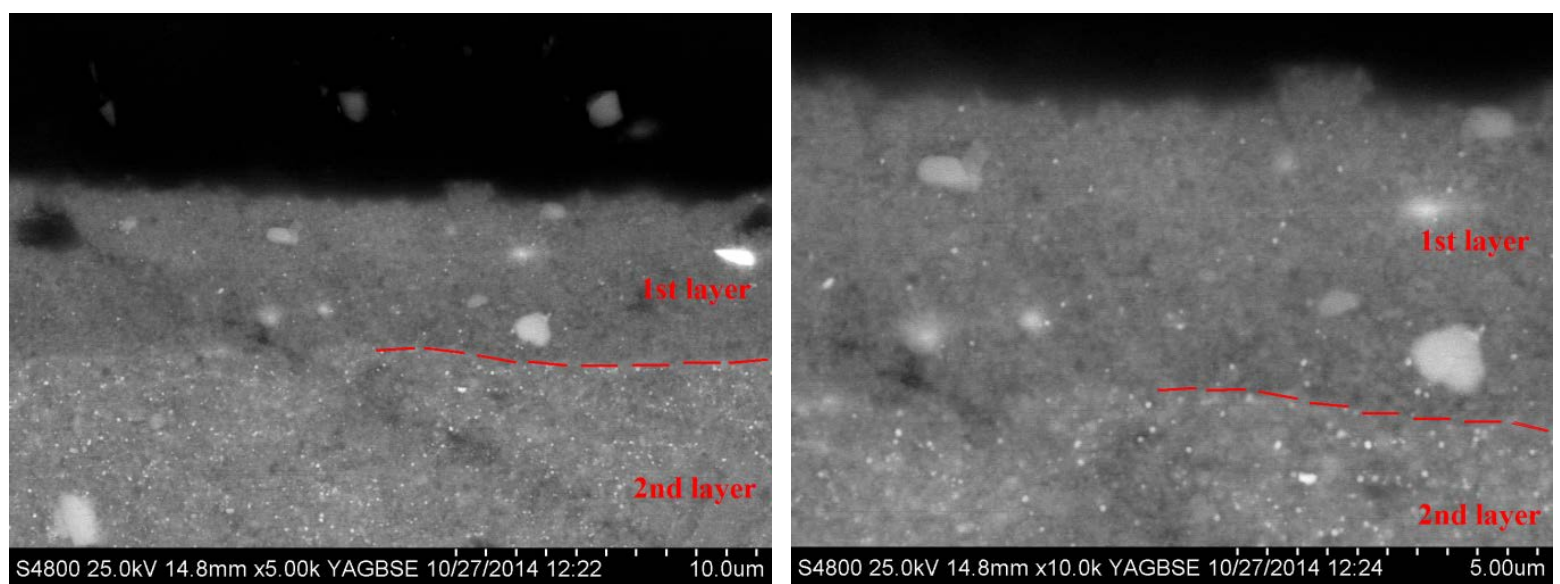

Figure.1. The SEM backscattered electron images of catalyst washcoat.

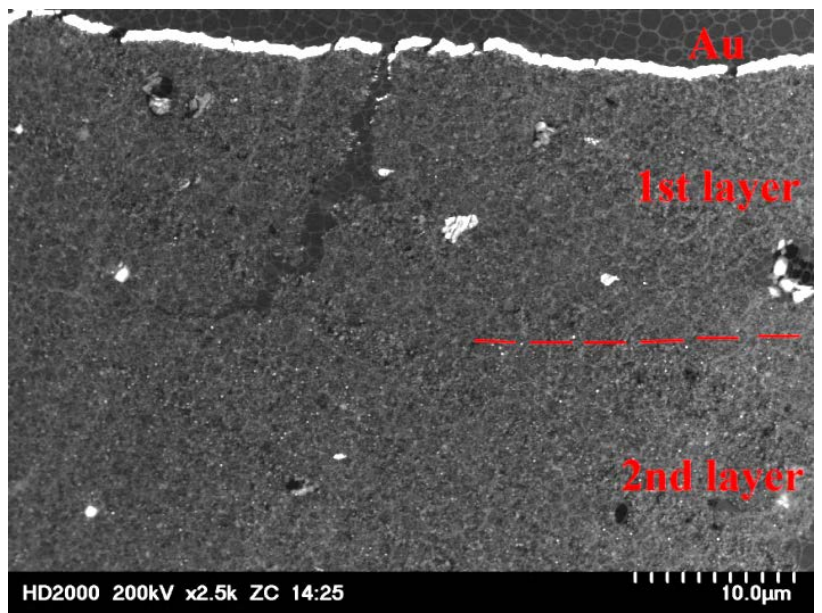

Figure.2. The S/TEM HAADF image of washcoat thin slice marked with gold layer.
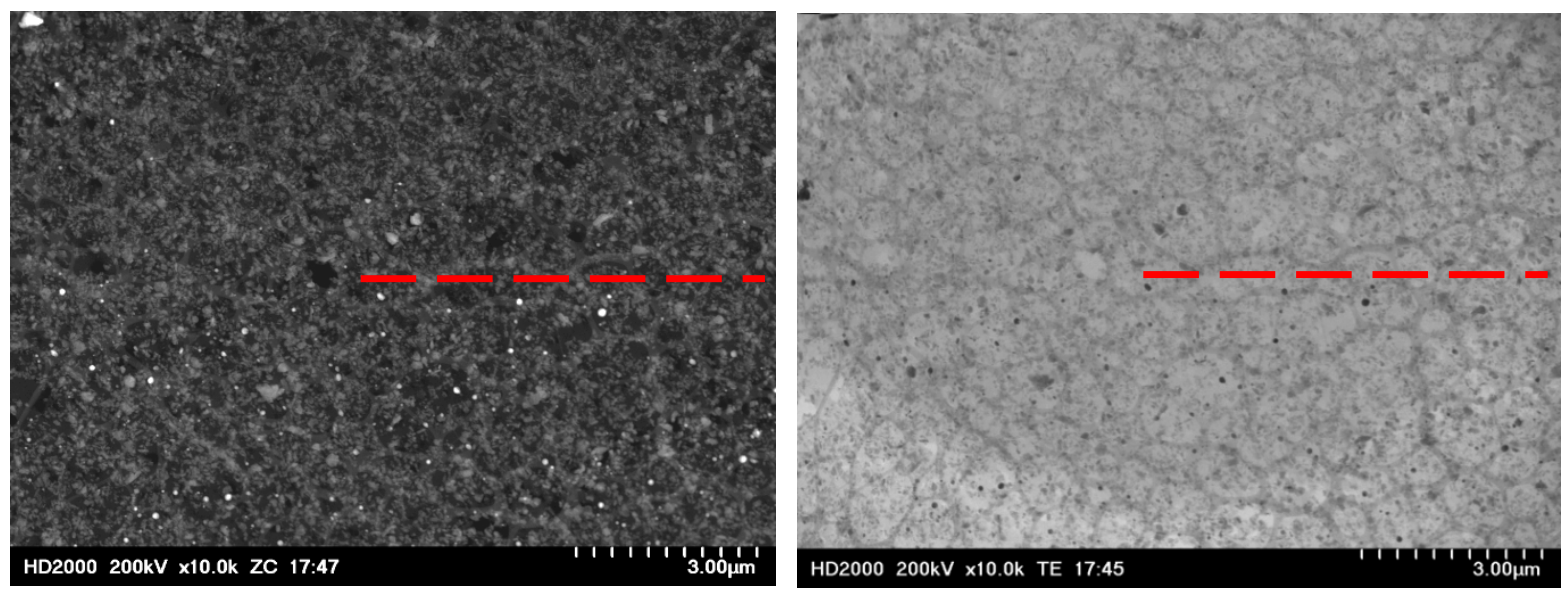

Figure.3. The interface between layers. The only difference is the lack of Ni nanoparticles at $1^{\text {st }}$ layer. 